\title{
ASSISTÊNCIA DE ENFERMAGEM PRESTADA ÀS MULHERES EM HEMODIÁLISE EM UM HOSPITAL DO TRIÂNGULO MINEIRO
}

\author{
NURSING CARE PROVIDED TO WOMEN ON HEMODIALYSIS IN A HOSPITAL OF \\ TRIÂNGULO MINEIRO
}

\author{
Lágila Cristina Nogueira Martins ${ }^{\mathrm{a}^{*}}$, ${ }^{\mathrm{b}}$ Maria Elizabeth Roza ${ }^{\mathrm{b}^{*}}$, Larínia Carolina Nogueira Martins ${ }^{\mathrm{c}^{* *}}$ \\ alagilaenfermeira@outlook.com, belizabethrz031@gmail.com, clariniacarolina@hotmail.com \\ *Universidade Federal de Uberlândia - Uberlândia (MG), Brasil \\ ** Universidade Federal do Triângulo Mineiro - Uberaba (MG), Brasil \\ Data de recebimento do artigo: 01/03/2017 \\ Data de aceite do artigo: 06/07/2017
}

\section{RESUMO}

Introdução: A hemodiálise corresponde a um tratamento rigoroso e contínuo, que acarreta limitaçôes físicas e psicológicas aos pacientes. Dessa forma, a assistência de enfermagem passa a ser indispensável para o enfrentamento das dificuldades encontradas e a adesão ao tratamento. Objetivos: $\mathrm{O}$ estudo em questáo visa analisar a qualidade da assistência de enfermagem prestada a mulheres em tratamento hemodialítico. Materiais e métodos: Trata-se de uma pesquisa descritiva, transversal e de campo, com abordagem qualitativa, realizada no setor de hemodiálise de um hospital universitário do Triângulo Mineiro/MG. Resultados: A partir da análise das respostas, foi possível perceber que a maioria das mulheres classificou a assistência de enfermagem e as informaçóes passadas como satisfatórias para o tratamento. Conclusão: Percebe-se, dessa forma, que o cuidado da equipe de enfermagem está direcionado não apenas para evitar as complicaçôes que podem estar presentes durante as sessôes de hemodiálise, mas também no enfrentamento das ansiedades e na consequente aceitação da doença e adesão ao tratamento, além de haver esclarecimento das dúvidas dos pacientes e de seus familiares.

Palavras-chave: Educação em enfermagem; unidades hospitalares de hemodiálise; qualidade de vida.

\section{ABSTRACT}

Introduction: Hemodialysis corresponds to a rigorous and continuous treatment, which brings physi$\mathrm{cal}$ and psychological limitations to patients. This way, nursing care becomes indispensable for coping with the difficulties found and adhesion to treatment. Objectives: This study aims to analyze the quality of nursing care provided to women on hemodialysis. Materials and methods: This is a descriptive, cross-sectional field research with a qualitative approach, that it was done in the hemodialysis sector of a University Hospital of Triângulo Mineiro/MG. Results: Analyzing the answers, it was possible to observe that the majority of women classified the nursing care and the information provided to them as satisfactory for their treatment. Conclusion: This way, nursing care is directed not only to avoid the complications that may be present during the hemodialysis sessions, but also to cope with the anxieties and consequent acceptance of the disease and adhesion to treatment, as well as clarification of the doubts of the patients and their relatives.

Keywords: Nursing education; hemodialysis hospital units; quality of life. 


\section{Introdução}

A doença renal crônica (DRC) é multicausal e corresponde a um problema de saúde pública mundial cada vez mais frequente, sendo que sua evolução está relacionada a altas taxas de morbimortalidade ${ }^{1}$. É uma doença incurável e consiste em lesão no parênquima renal e diminuição lenta, progressiva e irreversível da função renal. Justamente por essa evolução lenta, os pacientes podem permanecer assintomáticos por um longo período. Os sintomas como anemia leve, hipertensão, edema de olhos e pés, mudança nos hábitos e no aspecto da urina serão percebidos quando já houver perda de aproximadamente $50 \%$ da função renal ${ }^{1,2}$. A DRC é avaliada a partir da filtraçáo glomerular (FG) por um período igual ou superior a três meses e associada à perda das funções regulatórias, excretoras e endócrinas do rim. Uma taxa de $\mathrm{FG}<15 \mathrm{ml} / \mathrm{min} / 1,73 \mathrm{~m}^{2}$ denomina-se falência funcional renal (FFR), sendo necessário, portanto, terapia renal substitutiva (TRS) ${ }^{1}$.

Uma das formas de TRS mais utilizada na atualidade é a hemodiálise, que realiza o processo de filtragem e depuraçáo do sangue, correspondendo a uma parte da função renal que o rim doente não consegue mais realizar, sendo esta ligada à eliminaçáo de resíduos indesejáveis como a creatinina, a ureia, o excesso de sal e líquidos, além de controlar a pressão arterial $^{3}$. No entanto, a realização de hemodiálise também pode acarretar complicaçôes como: hipotensão arterial, câimbras, arritmias cardíacas, reaçóes alérgicas, síndrome do desequilíbrio da diálise, cefaleia e hipoglicemia ${ }^{4}$.

As sessôes de hemodiálise têm duraçâo de aproximadamente quatro horas, e são necessárias pelo menos três sessōes por semana. É um tratamento contínuo, por toda a vida, ou até que o transplante renal ocorra e seja bem-sucedido, que acarreta sérias mudanças na vida do paciente e de seus familiares, entretanto representa uma esperança de vida, sendo que as dificuldades encontradas na adesão ao tratamento estáo relacionadas à não aceitação da doença, à falta de apoio familiar e social e à dificuldade de percepção de si próprio ${ }^{2}$.

Além disso, o aumento da expectativa de vida também justifica o crescimento do número de pacientes em tratamento dialítico nos últimos anos, pois, com isso, há a elevação do número de doenças crônicas não transmissíveis (DCNT) como hipertensão arterial sistêmica e diabetes mellitus, que são fatores de risco para a doença renal crônica (DRC) e consequente falência funcional renal (FFR). Sabe-se que no Brasil houve um aumento considerável de pessoas com DRC nos últimos anos, cujo prognóstico ainda não é bom, além de os custos serem altos, o que faz com que as taxas de morbimortalidade ainda sejam altas, somado ao fato de faltar vagas nas clínicas de hemodiálise, até mesmo porque essas não cresceram conforme a demanda de pacientes ${ }^{1-3,5-6}$.

Assim, percebe-se que os avanços tecnológicos e terapêuticos contribuem para o aumento da sobrevida dos pacientes com DRC, entretanto não lhes possibilitam qualidade de vida e inclusive geram diversos graus de limitação física, emocional, assim como limitações no trabalho e lazer, além das bruscas mudanças em suas vidas, que podem causar desânimo, desespero, sofrimento e, por vezes, abandono do tratamento - por isso a necessidade de orientação e acompanhamento de profissionais que estimulem as capacidades dos pacientes e propiciem a adaptação ao novo estilo de vida ${ }^{1}$.

A enfermagem tem um papel importante no cuidado a esses pacientes, seja no âmbito educacional, ajudando na adesão e não abandono do paciente ao tratamento, seja estimulando e orientando sobre o autocuidado, ou ainda, no enfrentamento das mudanças físicas e psicológicas, o que garante o bem-estar do paciente ${ }^{7}$. A partir de uma maior proximidade com o paciente é que o enfermeiro será capaz de planejar intervençóes que realmente possam ajudar na nova realidade do paciente. A orientação deve ser sobre a enfermidade e sobre tudo o que envolve as formas de terapia, seus riscos, seus benefícios e suas restriçôes. Essas orientaçôes são importantes para diminuir o estresse inicial e as intercorrências, aumentar a adesão ao esquema terapêutico e estimular o autocuidado ${ }^{1,7}$.

Os cuidados de enfermagem estão presentes em todas as etapas do tratamento, desde a entrada no serviço de hemodiálise até o final da sessão, voltados sempre ao bem-estar do paciente, além de promover educação em saúde para a sensibilização deste e de seus familiares ${ }^{1-2}$.

Diante disso é que se propõe este estudo, especificando as mulheres como público-alvo, com o intuito de verificar como elas conciliam todas as suas atividades diárias de mães, esposas, donas de casa e trabalhadoras formais com a doença e com o tratamento contínuo, principalmente nos tempos atuais, em que as mulheres estão cada vez mais inseridas no mercado de trabalho. Refletindo sobre isso, optou-se por desenvolver este estudo, que tem os objetivos de analisar a qualidade da assistência de enfermagem prestada a essa população e caracterizar tal grupo quanto às variáveis sociodemográficas, clínicas e hábitos de vida.

\section{Materiais e métodos}

Corresponde a um recorte de trabalho de conclusáo de curso realizado na Universidade Federal de Uberlândia. A coleta dos dados foi feita nos meses de setembro e outubro de 2015, no período da manhã e da tarde, após aprovação pelo Comitê de Ética 
em pesquisa, protocolo $\mathrm{n}^{\circ}$ 1.213.009 (CAAE $\mathrm{n}^{\circ}$ 45868115.7.0000.5152) e de acordo com a Resolução no 466/12 do Conselho Nacional de Saúde.

Trata-se de uma pesquisa do tipo descritiva, transversal, de campo, com abordagem qualitativa, realizada no setor de hemodiálise de um hospital universitário do Triângulo Mineiro/MG, onde foram avaliadas todas as mulheres em tratamento hemodialítico que preenchiam os critérios de inclusão, ou seja, sexo feminino, maiores de 18 anos, portadoras de DRC e que estavam em tratamento hemodialítico no referido setor, sendo, dessa forma, 19 mulheres. Utilizou-se para a coleta um instrumento sociodemográfico para caracterização da amostra e ainda algumas questóes, tanto abertas como fechadas, referentes à assistência de enfermagem, formuladas pela própria pesquisadora, as quais complementaram o instrumento de coleta de dados utilizado no trabalho de conclusão de curso.

A participaçáo das entrevistadas foi condicionada à assinatura do Termo de Consentimento Livre e Esclarecido (TCLE), o qual autorizou a coleta de dados e a utilizaçáo destes. A entrevista teve início com a aplicação do questionário, e as questóes abertas foram transcritas pela pesquisadora e posteriormente lidas ao paciente para confirmar se o que foi transcrito estava ou não correto. As mulheres também foram identificadas com as iniciais P1, P2, P3 e assim por diante, para manter o sigilo e preservar a identidade das participantes. Os dados possuem finalidade acadêmica e de publicação.

\section{Resultados}

Quanto às variáveis sociodemográficas abordadas neste estudo, realizou-se levantamento da idade, cor da pele, escolaridade e estado civil, e se as mulheres entrevistadas residiam sozinhas. Já a variável econômica abordada foi a ocupação destas. Em relação às variáveis clínicas, avaliou-se a obesidade e se as mulheres eram idosas ou não. Quanto aos hábitos de vida, as participantes foram interrogadas quanto à prática de atividade física, etilismo e tabagismo. As informaçôes encontradas podem ser visualizadas na Tabela 1 .

Tabela 1: Descrição das variáveis sociodemográficas, clínicas, econômicas e dos hábitos de vida das mulheres em tratamento hemodialítico. Triângulo Mineiro/MG, 2015.

\begin{tabular}{|c|c|c|c|c|c|}
\hline \multicolumn{6}{|c|}{ Dados sociodemográficos, clínicos, econômicos e hábitos de vida } \\
\hline Faixa etária & $\mathbf{N}$ & $\%$ & Estado civil & $\mathbf{N}$ & $\%$ \\
\hline $21-30$ anos & 2 & $10,53 \%$ & Solteira & 7 & $36,83 \%$ \\
\hline $31-40$ anos & 4 & $21,05 \%$ & Casada & 8 & $42,11 \%$ \\
\hline $41-50$ anos & 3 & $15,79 \%$ & Viúva & 2 & $10,53 \%$ \\
\hline $51-60$ anos & 5 & $26,31 \%$ & Separada & 2 & $10,53 \%$ \\
\hline $61-70$ anos & 3 & $15,79 \%$ & Cor da pele & $\mathbf{N}$ & $\%$ \\
\hline 71-80 anos & 2 & $10,53 \%$ & Branca & 5 & $26,31 \%$ \\
\hline Idoso & $\mathbf{N}$ & $\%$ & Não branca & 14 & $73,69 \%$ \\
\hline Sim & 5 & $26,31 \%$ & Nível de escolaridade & $\mathbf{N}$ & $\%$ \\
\hline Não & 14 & $73,69 \%$ & Não Alfabetizada & 2 & $10,53 \%$ \\
\hline Profissão & $\mathbf{N}$ & $\%$ & Ensino Fund. Incompleto & 8 & $42,11 \%$ \\
\hline Doméstica & 2 & $10,53 \%$ & Ensino Fund. Completo & 3 & $15,79 \%$ \\
\hline Do lar & 10 & $52,64 \%$ & Ensino med. Incompleto & 1 & $5,26 \%$ \\
\hline Aposentada & 4 & $21,05 \%$ & Ensino med. Completo & 5 & $26,31 \%$ \\
\hline Cabelereira & 1 & $5,26 \%$ & Pratica exercício físico & $\mathbf{N}$ & $\%$ \\
\hline Costureira & 1 & $5,26 \%$ & Sim & 3 & $15,79 \%$ \\
\hline Cozinheira & 1 & $5,26 \%$ & Não & 16 & $84,21 \%$ \\
\hline Religião & $\mathbf{N}$ & $\%$ & Obesidade & $\mathbf{N}$ & $\%$ \\
\hline Católica & 11 & $57,9 \%$ & Sim & 5 & $26,3 \%$ \\
\hline Evangélica & 6 & $31,57 \%$ & Não & 14 & $73,7 \%$ \\
\hline Espírita & 2 & $10,53 \%$ & Etilista & $\mathbf{N}$ & $\%$ \\
\hline Reside sozinho & $\mathbf{N}$ & $\%$ & Sim & 0 & 0 \\
\hline Sim & 1 & $5,26 \%$ & Náo & 19 & $100 \%$ \\
\hline \multirow[t]{3}{*}{ Não } & 18 & $94,74 \%$ & Tabagista & $\mathbf{N}$ & $\%$ \\
\hline & & & Sim & 2 & $10,53 \%$ \\
\hline & & & Não & 17 & $89,47 \%$ \\
\hline
\end{tabular}


As mulheres em tratamento hemodialítico no setor do hospital em que o estudo foi realizado também foram questionadas sobre a assistência de enfermagem e as informaçóes recebidas neste, garantindo, dessa forma, um espaço no qual as entrevistadas puderam dar sua opiniáo em relação ao trabalho prestado pela equipe de enfermagem, permitindo assim verificar a necessidade ou não de melhoria. A maioria das entrevistadas, ou seja, 18 mulheres $(94,74 \%)$, classificou a assistência recebida como satisfatória. Somente uma $(5,26 \%) \mathrm{mu}-$ lher considerou a assistência pouco satisfatória, conforme pode ser observado na Tabela 2 .

Tabela 2: Distribuição das respostas em relação à qualidade da assistência de enfermagem e das informações passadas às pacientes. Triângulo Mineiro/]MG, 2015.

\begin{tabular}{|c|c|c|}
\hline \multicolumn{3}{|c|}{ Avaliaçáo da assistência de enfermagem } \\
\hline & $\mathbf{n}$ & $\%$ \\
\hline Insatisfatória & 0 & 0 \\
\hline Indiferente & 0 & 0 \\
\hline Pouco satisfatória & 1 & 5,26 \\
\hline Satisfatória & 18 & 94,74 \\
\hline \multicolumn{3}{|c|}{ Avaliaçáo das informaçóes passadas pelos enfermeiros } \\
\hline & n & $\%$ \\
\hline Insatisfatória & 0 & 0 \\
\hline Indiferente & 1 & 5,26 \\
\hline Pouco satisfatória & 1 & 5,26 \\
\hline Satisfatória & 17 & 89,48 \\
\hline \multicolumn{3}{|c|}{ Avaliaçáo da assistência de enfermagem na ajuda ao tratamento } \\
\hline & n & $\%$ \\
\hline Sim & 19 & 100 \\
\hline Não & 0 & 0 \\
\hline
\end{tabular}

Além disso, elas foram questionadas a respeito das informaçóes passadas pela equipe de enfermagem durante o tratamento de hemodiálise, se estas eram satisfatórias, indiferentes, pouco satisfatórias ou insatisfatórias para o bom desenvolvimento dos procedimentos e também da qualidade de vida dessas mulheres, uma considerou como indiferente $(5,26 \%)$ e outra como pouco satisfatórias $(5,26 \%)$ as informações recebidas, o restante, portanto, 17 mulheres $(89,48 \%)$, classificou como satisfatórias (Tabela 2).

Em relação à pergunta: "Você acha que a assistência de enfermagem ajuda no enfrentamento do seu tratamento e nas dificuldades do dia a dia?", todas as mulheres responderam que sim e inclusive explicaram o porquê, demonstrando a importância que a assistência de enfermagem representa para elas e como auxilia na adesão ao tratamento. Tais respostas podem ser verificadas na Tabela 2 deste artigo.

\section{Discussão}

Apesar de a pesquisa ter uma população reduzida, o que também corresponde a uma limitação quando comparada a outros estudos já realizados, as informações coletadas são de grande importância para análise e melhoria da assistência de enfermagem prestada a esses pacientes, auxiliando assim na superaçáo das dificuldades e limitaçóes do dia a dia.

A partir da avaliação dos dados demonstrados na Tabela 1 deste trabalho, pode-se dizer que o perfil da população estudada foi: predomínio da idade entre 51 e 60 anos; mulheres que convivem com companheiro, filhos(as) e /ou outro(s) familiar(es); cor da pele não branca; religião católica; baixa escolaridade; ocupação com serviços gerais/ domésticos ou aposentadas. Além disso, a maioria das mulheres (14) foi considerada náo obesa, ou seja, o IMC encontrado foi menor que $30 \mathrm{~kg} / \mathrm{m}^{2}$. 
Confirmando o que foi encontrado, outros estudos também trazem que o maior número de pacientes em tratamento hemodialítico possui entre 45 e 64 anos. $\mathrm{O}$ aumento da faixa etária em tratamento hemodialítico está relacionado à inversão da pirâmide etária e ao consequente aumento de doenças crônicas não transmissíveis (DCNT), que podem ser base para a doença renal crônica (DRC). Além disso, a idade do paciente influencia na sua qualidade de vida, assim como pode interferir na aceitação e percepção da doença, por isso a necessidade de uma assistência de enfermagem de qualidade para a promoção de educação em saúde, prevenção de complicaçóes e correta adesão ao tratamento ${ }^{8-10 .}$

Quanto à ocupação, muitas mulheres foram impedidas de realizar as suas atividades de trabalho devido ao tratamento debilitante e contínuo a que estão submetidas, o que acarreta sentimentos de inferioridade e limitação, já que o trabalho é extremamente importante para a autorrealização profissional e satisfação das necessidades de sobrevivência. Outras atividades que também ficam prejudicadas com o tratamento em questão são as viagens e atividades de lazer, afetando ainda mais a qualidade de vida desses pacientes ${ }^{11,12 .}$ Justamente por tratar-se de um evento traumático, os pacientes necessitam de apoio e de informaçóes confiáveis dos profissionais responsáveis pelo seu tratamento sobre o estado de saúde em que se encontram e muitas vezes se apegam à fé e religiáo na tentativa de superar ou pelo menos aceitar tal realidade, isso pode ser comprovado pelos dados obtidos neste estudo. Além da religião, também buscam ajuda em seus parceiros e familiares, correspondendo a primeira rede de apoio social ${ }^{9,13-15}$.

Em relação à escolaridade, a maioria das mulheres possuía ensino fundamental incompleto, ou seja, baixo nível escolar, o que pode interferir na capacidade de resolução de problemas e obtenção de informações para a prevenção de agravos e adoção de hábitos de vida saudáveis ${ }^{16-17}$.

Em relação aos hábitos de vida, também se obteve dados preocupantes, já que dezesseis mulheres se consideraram sedentárias, sendo que estudos demonstram a importância da prática de atividade física para o controle pressórico, diminuição do uso de anti-hipertensivos, aumento da capacidade funcional, da força e da resistência muscular, melhora da função cardíaca e, consequentemente, da qualidade de vida ${ }^{17-18}$. Etilismo, tabagismo e peso também não podem ser deixados de lado, já que são fatores agravantes para a insuficiência renal crônica ${ }^{19}$, e mesmo que apenas duas mulheres relataram ser fumantes e somente cinco delas possuíam IMC maior que $30 \mathrm{~kg} / \mathrm{m}^{2}$, sabe-se que a obesidade, o tabagismo e o etilismo geralmente estão associados à diabetes mellitus e hipertensão, que são as principais doenças de base da DRC, correspondendo a um fator de risco para o desenvolvimento de lesão glomerular e progressão para $\mathrm{FFR}^{19}$.

Outro importante tema a ser discutido é a explicaçáo a respeito da escolha de mulheres como público-alvo. Sabe-se que ao longo da história, homens e mulheres exerciam papéis sociais distintos, e essas diferenças eram valorizadas, prejudicando assim a figura feminina. Entretanto as mulheres, juntamente com os movimentos feministas, lutaram de forma gradativa pelo ingresso acadêmico, por condiçóes adequadas de vida, pela ausência de desigualdade entre os gêneros, pela liberdade sexual, pela participação no mercado de trabalho, pela construção e obtenção de identidade, ou seja, pela conquista de seus direitos e sobretudo de cidadania. Atualmente, percebe-se a grande mudança nos perfis das mulheres, que passaram inclusive a exercer e acumular uma série de atividades e competir de igual para igual com os homens ${ }^{20}$, e por isso a ênfase nessas mulheres, que mesmo com o tratamento contínuo, ainda exercem uma série de atividades na vida pessoal e profissional, necessitando ainda mais do apoio de pessoas próximas e de profissionais de saúde que realmente saibam reconhecer o valor de cada uma delas.

Por tratar-se de pacientes críticos, os renais crônicos necessitam de um tratamento especializado, com profissionais que possuam conhecimento suficiente para prestar uma assistência de forma adequada, e sobretudo, humanizada. Os cuidados envolvem desde a entrada do paciente até a sua saída das sessóes de hemodiálise. A educação e assistência do paciente renal é de responsabilidade do enfermeiro, mesmo porque é o profissional que está mais próximo ao paciente. Dessa forma, cabe aos mesmos planejar as intervençôes necessárias, estar atentos aos sinais vitais, ao funcionamento adequado das máquinas, à anticoagulação, ao conforto do paciente, às intercorrências, à necessidade da presença do médico e ao esclarecimento das dúvidas que podem surgir ${ }^{21}$.

Nesse sentido, as mudanças provocadas pelo tratamento atingem também os familiares dos pacientes, já que precisam ajustar as suas rotinas diárias a fim de atender as necessidades do paciente com insuficiência renal crônica, no que diz respeito a apoio familiar. Assim, os profissionais da enfermagem precisam saber como abordar os familiares nos planos de cuidados, além de prestar a assistência necessária a eles ${ }^{22}$.

A função do enfermeiro não é apenas executar técnicas e procedimentos, mas sim desenvolver habilidades de comunicação, apoio e empatia, satisfazendo as necessidades dos pacientes. Dessa forma, a enfermagem desenvolve pesquisas preocupando-se com a qualidade de vida de pacientes com doenças crônicas, a fim de 
investir no aumento da expectativa de vida, com êxito, desses pacientes ${ }^{22}$. Para tanto, é necessário atuar de forma mais próxima do paciente, conhecendo as suas percepçóes e limitaçóes diante do tratamento, para que assim seja possível estabelecer formas de enfrentamento das situaçóes adversas e consequente melhoria da qualidade de vida, mesmo porque, percebe-se que o modo como cada paciente convive com a IRC é sempre único e pessoal, e depende de seu perfil psicológico e das condiçóes ambientais e sociais em que está inserido ${ }^{8-23}$.

Ouvir os sujeitos que vivenciam tal doença e compreendê-los é extremamente importante para a enfermagem e para outros profissionais da saúde a fim de que estes possam prestar os cuidados necessários e auxiliá-los a viver bem e com qualidade apesar das limitaçôes que o tratamento traz ${ }^{22}$.

Ao analisar as respostas obtidas, presentes na Tabela 2, encontrou-se uma contradição, já que uma mulher considerou a assistência de enfermagem que recebia pouco satisfatória e em relação às informaçoóes passadas pelos enfermeiros, uma considerou insatisfatória e uma como pouco satisfatória, mas quando tiveram que avaliar se a assistência de enfermagem ajudava no tratamento e nas dificuldades do dia a dia, todas as mulheres disseram que sim e ainda explicaram o porquê. Isso mostra como alguns pacientes apresentam certa dificuldade para entender adequadamente as questóes solicitadas nos instrumentos de coleta de dados e por vezes acabam respondendo de forma contraditória. Mesmo assim, foi possível perceber que todas as mulheres se sentiram beneficiadas com a assistência de enfermagem que recebem durante as sessóes de hemodiálise, no setor em que o estudo foi realizado, mostrando como esta pode ser benéfica para o enfrentamento de tal realidade, que afeta o indivíduo não somente física, mas também psicologicamente. Todos os discursos, de quando elas foram interrogadas sobre os benefícios que as informaçóes passadas pelos enfermeiros trazem às suas vidas, de forma geral, podem ser resumidos pelas palavras ajuda, orientação e saúde.

Para demonstrar esses discursos, as mulheres entrevistadas foram nomeadas com a inicial $\mathrm{P}$ de paciente $\mathrm{e}$ numeradas de um a dezenove, como forma de manter o sigilo e preservar a identidade de cada uma delas.

$$
\text { A gente fica satisfeita com o que elas falam. (P10) }
$$

Sempre traz (beneficios); ajuda na qualidade de vida, esclarece as dúvidas, porque nem sempre sabemos de tudo. (P11)

Me cuidar mais, ser ciente dos meus objetivos com o tratamento. (P12)
Melhor forma de cuidarmos da saúde; são informaçôes sobre tudo. (P13)

Conhecimento, esclarece as duividas. (P14)

Para mim está tudo bom; não tem o que reclamar. (P15)

Eles me acalmam, não tem o que falar porque é tudo bom; todos os enfermeiros merecem nota 10. Eu adoro todos eles. (P16)

Cuidar da minha saúde, minha chefe (enfermeira) é muito boa. (P17)

Como cuidar da alimentação, do cateter. (P18)

Elas falam o que eu posso comer; me ajudam muito. (P19)

Para gente ficar bom. (P09)

Tem os remédios que dão aqui; a relaçẫo entre a equipe e paciente, eles nos ajudam a entender a doença. (P08)

Para eu ter meus cuidados, seguir as orientaçôes. (P07)

Elas pegam no pé para não faltar. (P06)

Vários beneficios, elas explicam o nosso problema de saúde. (P04)

As informaçöes ajudam no tratamento; esclarecem as dúvidas, tiram o medo de realizar as sessóes. (P03)

Muito bom, você fica sabendo o que pode ou não fazer. (P02)

Aquelas mulheres que avaliaram as informações passadas pelos enfermeiros durante o tratamento como pouco satisfatórias ou indiferente também demonstraram gratidáo ao expor os benefícios que recebem com essas informações, confirmando a contradição encontrada e discutida anteriormente.

As informaçōes passadas ajudam no tratamento. (P01)

Melhor cuidado, explica o que deve e o que não deve ser feito; atenção com a gente. (P05)

Evidenciou-se que todas as pacientes afirmaram que a assistência de enfermagem ajuda no enfrentamento do próprio tratamento e das dificuldades do dia a dia, demonstrando assim a importância e necessidade da presença do enfermeiro durante as sessões de hemodiálise. 
A enfermagem tem muita paciência com a gente, muita calma. É muito importante, não teria o que fazer sem elas. (P01)

Ajuda a gente não desanimar, seguir em frente. (P02)

Acompanham o tratamento, as faltas, orientam a não faltar. (P03)

Porque têm paciência, ajuda a guardar os pertences, leva até o transporte. (P04)

No esclarecimento das dúvidas, do tratamento, passam esperança para nós. Dão muita força. (P05)

Porque sem elas, a gente não é nada; elas são muito importantes. Não tem o que reclamar; parece uma família. (P06)

Se não tivesse a assistência delas seria complicado; se fossem diferentes seria difícil ficar aqui três horas e meia. (P07)

Eles dão muita atenção, ficam atentos às especificidades de cada um para não desmaiar. (P08)

Porque é um apoio. (P09)

Porque orienta a gente, ajuda a náo apavorar a gente. (P10)

Se não fossem eles e sem a máquina não haveria tratamento. É preciso ter alguém que se dedica. (P11)

Melhorar a minha qualidade de vida em todos os aspectos. (P12)

Porque o pessoal trata a gente muito bem. E pelo fato de serem assim, nos sentimos bem nesse lugar, conversamos e distraímos; são pessoas que fazem parte de nossa vida. (P13)

Porque convive muitos anos, cria laços, eles se preocupam de verdade, não é uma relação de paciente e profissional; eles ligam, esclarecem as dúvidas, ajudam no enfrentamento. (P14)

$A$ assistência de enfermagem é boa, elas passam muitas informaçôes e me ajuda. (P15)

Me aconselham (se emocionou), eles são supimpa; eu gosto tanto deles que nem dou conta de falar. Em 15 anos nada de errado aconteceu comigo. (P16)

Ajuda porque elas passam o que devemos fazer ou deixar de fazer; são maravilhosas. (P17)

São pessoas boas demais, conversam com a gente. Se chegamos tristes eles querem saber porque. (P18)
Tem dia que a pressáo cai ou dá câimbra e elas me socorrem. (P19)

A partir das respostas mencionadas, percebe-se que o cuidado de enfermagem está direcionado não somente para evitar as complicaçóes que podem estar presentes durante as sessóes de hemodiálise, mas também no enfrentamento das ansiedades, na consequente aceitação da doença e na adesáo ao tratamento. Muitas vezes esses profissionais passam a ser vistos como familiares, pelo longo período de convívio e pelas preocupaçóes e cuidados que realizam com os pacientes. É de extrema importância a divulgação de informaçóes e o esclarecimento de dúvidas, tanto ao paciente como para seus familiares, sobre a doença, a forma de tratamento, as necessidades de adaptações à nova realidade, e sobretudo o apoio emocional devido às intensas transformaçôes e limitaçóes que surgem no cotidiano do paciente.

Dessa forma, a presença do enfermeiro é indispensável, pois é o profissional que vai estar em contato direto com o paciente, seus familiares e o restante da equipe, proporcionando uma assistência de qualidade, além da criação de vínculo muito maior do que somente o relacionamento enfermeiro-paciente. Assim, o profissional de enfermagem precisa ter domínio náo somente das tecnologias que envolvem o tratamento, mas também na dimensão emocional e social, atendendo todas as necessidades dos pacientes ${ }^{22,24}$.

Entende-se que a descoberta de uma doença crônica e a necessidade de tratamento contínuo, por se tratar de uma doença incurável, é encarada com dificuldade pelos pacientes. Além de ocasionar sofrimento físico e psíquico nestes, a sensação de dependência de uma máquina está presente. Porém, esses sentimentos são modificados ao longo da hemodiálise, podendo muitas vezes desaparecer, quando percebem a importância do tratamento e como este é fundamental para a vida de pacientes com insuficiência renal crônica ${ }^{9,22}$.

Assim, é importante que os profissionais de enfermagem, juntamente com outros profissionais da saúde, preocupem-se em desenvolver açóes de educação em saúde direcionadas às pessoas com problemas renais, evitando o diagnóstico tardio e investindo na conscientização da população a respeito da prevenção dessa doença, devido aos vários agravos que esta traz para a vida do indivíduo, o que afeta inclusive o papel desempenhado por este na sociedade.

Além disso, é importante que a enfermagem também conscientize a família a prestar todo apoio necessário e vença os preconceitos existentes para que o paciente consiga enfrentar as suas restriçóes e os seus sentimentos negativos, aceitar e valorizar o tratamento, para assim ter a possibilidade de melhorar sua qualidade de vida ${ }^{9,22}$. 
A enfermagem sempre deve valorizar a individualidade dos pacientes e a humanização do atendimento, para que assim eles se sintam estimulados a participar de atividades de promoçáo de saúde e esclarecer suas dúvidas a respeito do tratamento e que consigam atuar na sociedade sentindo-se, dessa forma, mais ativos ${ }^{22}$.

Percebe-se, assim, a importância de criar estratégias de intervençôes a pacientes com DRC para o real atendimento de suas necessidades e a promoçáo de uma melhor qualidade de vida a estes, a otimização do tratamento hemodialítico, a oferta de cuidados mais qualificados tanto da equipe de enfermagem quanto dos familiares, além de o incentivo a novas pesquisas na área.

\section{Conclusão}

De acordo com as respostas obtidas, a assistência de enfermagem foi considerada como indispensável, mesmo porque o enfermeiro é o profissional que está em contato direto com o paciente, atendendo não somente as necessidades destes, mas também de seus familiares, esclarecendo as dúvidas e criando vínculos, de forma individual e humanizada. As pacientes classificaram como satisfatória a assistência de enfermagem prestada e as informaçôes recebidas no setor de hemodiálise do hospital em que a pesquisa foi realizada, considerando essas como essenciais no enfrentamento das dificuldades do tratamento e do dia a dia.

Diante do exposto, visando a uma melhor qualidade de vida para essas pacientes, é imprescindível que os profissionais de enfermagem desenvolvam continuamente açôes de educação em saúde, conscientizem a população a respeito da prevenção de doenças de base, tratamento e controle adequado para evitar complicaçóes, promovam orientaçôes sobre o tratamento necessário e esclareçam as dúvidas e, sobretudo, conscientizem a família a prestar todo apoio necessário a essas pacientes, para que estes consigam vencer preconceitos dos quais são vítimas, restrições e sentimentos negativos. Estes profissionais necessitam contribuir efetivamente para melhora da qualidade de vida desses pacientes, realizando buscas contínuas na literatura e na prática para criar ou aprimorar estratégias de intervençóes e assim melhorar a assistência e o enfrentamento da doença pelos pacientes.

\section{Agradecimentos}

Primeiramente agradecemos a Deus, por iluminar e proteger nossos caminhos, aos nossos familiares, pelo apoio contínuo e a todos aqueles que direta ou indiretamente nos auxiliaram na construção da pesquisa e do artigo em si. O nosso muito obrigada.

\section{Referências}

1. Bastos MG, Bregman R, Kirsztajn GM. Doença renal crônica: frequente e grave, mas também prevenível e tratável. Rev Assoc Med Bras. 2009;56(2):248-53.

2. Santana SS, Fontenelle T, Magalhães LM. Assistência de enfermagem prestada aos pacientes em tratamento hemodialítico nas unidades de nefrologia. Rev Científica do ITPAC. 2013;6(3):1-11.

3. Cabral AS. O que é hemodiálise? [Internet]. São Paulo: Sociedade Brasileira de Nefrologia. 2017 [citado em 2015 mar 28]. Disponível em: https://goo.gl/wtmfK7

4. Castro, MCM. Atualização em diálise: Complicaçôes agudas em hemodiálise. J Bras Nefrol. 2001;23(2):108-13.

5. Crestani Filho VJ, Rodrigues RAC. Progression of chronic kidney disease: ambulatory experience in Santarém Pará. J Bras Nefrol [Internet]. 2013 [citado em 2016 mar 17];35(2):99-106. Disponível em: https://goo.gl/EMkhPX

6. Cabral AS. Carta da nefrologia [Internet]. São Paulo: Sociedade Brasileira de Nefrologia. 2017 [citado 2017 jul 02]. Disponível em: https://sbn.org.br/carta-da-nefrologia/

7. Santos I, Rocha RPF, Berardinelli LMM. Necessidades de orientação de enfermagem para o autocuidado de clientes em terapia de hemodiálise. Rev Bras Enferm. 2011;64(2):335-42.

8. Guedes KD, Guedes HM. Qualidade de vida do paciente portador de insuficiência renal crônica. Rev Ciênc Saúde. 2012;5(1):48-53.

9. Takemoto AY, Okubo P, Bedendo J, Carreira L. Avaliação da qualidade de vida em idosos submetidos ao tratamento hemodialítico. Rev Gaucha Enferm. 2011;32(2):256-62.

10. Soares KTA, Viesser MV, Rzniski TAB, Brum EP. Eficácia de um protocolo de exercícios físicos em pacientes com insuficiência renal crônica, durante o tratamento de hemodiálise, avaliada pelo SF-36. Fisioter Mov. 2011;24(1):133-40.

11. Reis CK, Guirardello EB, Campos CJG. O indivíduo renal crônico e as demandas de atenção. Rev Bras Enferm. 2008;61(3):336-41.

12. Santos TMB, Frazão IS. Qualidade de vida dos trabalhadores que realizam hemodiálise. Rev Ciênc Méd. 2012;21(1-6):5-14.

13. Silva AS, Silveira RS, Fernandes GFM, Lunardi VL, Backes VMS. Percepçóes e mudanças na qualidade de vida de pacientes submetidos à hemodiálise. Rev Bras Enferm. 2011;64(5):839-44.

14. Terra FS, Costa AMDD. Avaliação da qualidade de vida de pacientes renais crônicos submetidos à hemodiálise. Rev Enferm UERJ. 2007;15(3):430-36.

15. Valcanti CC, Chaves ECL, Mesquita AC, Nogueira DA, Carvalho EC. Religious/spiritual coping in people with chronic kidney disease undergoing hemodialysis. Rev Esc Enferm USP. 2012;46(8):838-45. 
16. Erbs GC, Nerbass FB, Silva RMG, Luz Filho HA, Vieira MA. A influência da escolaridade na qualidade de vida de pacientes em diálise [Internet]. Joinville: Fundação Pró Rim. 2011 [citado em 2017 set 22]. Disponível em: https://goo.gl/5RQfbr

17. Pessuto J, Carvalho EC. Fatores de risco em indivíduos com hipertensão arterial. Rev Lat Am Enfermagem. 1998;6(1):33-9.

18. Moura RMF, Silva FCR, Ribeiro GM, Sousa LA. Efeitos do exercício físico durante a hemodiálise em indivíduos com insuficiência renal crônica: uma revisão. Fisioter Pesqui. 2008;15(1):86-91.

19. Paula RB, Fernandes NC, Carmo VMP, Andrade LCF, Bastos MG. Obesidade e doença renal crônica. J Bras Nefrol. 2006;28(3):158-64.
20. Menezes WN. Cidadania feminina: um longo e tortuoso caminho. Emancipação. 2005;5(1):53-69.

21. Cesarino CB, Borges PP, Ribeiro RCHM, Ribeiro DF, Kusumota L. Avaliação do risco cardiovascular de pacientes renais crônicos segundo critérios de Framingham. Acta Paul Enferm. 2013;26(1):101-7.

22. Silva AS, Silveira RS, Fernandes GFM, Lunardi VL, Backes VMS. Percepçóes e mudanças na qualidade de vida de pacientes submetidos à hemodiálise. Rev Bras Enferm. 2011;64(5):839-44.

23. Nascimento CD, Marques IR. Intervenções de enfermagem nas complicações mais frequentes durante a sessão de hemodiálise: revisão da literatura. Rev Bras Enferm. 2005;58(6):719-22.

24. Gullo ABM, Lima AFC, Silva MJP. Reflexóes sobre comunicação na assistência de enfermagem ao paciente renal crônico. Rev Esc Enferm USP. 2000;34(2):209-12.

\section{Como citar este artigo:}

Martins LCN, Roza ME, Martins LCN. Assistência de enfermagem prestada às mulheres em hemodiálise em um hospital do triângulo mineiro. Rev. Aten. Saúde. 2017;15(53):28-36. 